\title{
LOS SONETOS DE LA MUERTE: REPRESENTAÇÕES IDENTITÁRIAS E DA MEMÓRIA EM GABRIELA MISTRAL
}

\author{
LOS SONETOS DE LA MUERTE: REPRESENTATIONS OF \\ IDENTITY AND MEMORY IN GABRIELA MISTRAL
}

Francemilda Lopes do Nascimento ${ }^{1}$

Este ensaio tem como foco principal refletir sobre os elementos identitários presentes em Gabriela Mistral e, refletindo-se em sua escrita, bem como os "elementos" da memória que se entrecruzam com a identidade a partir de uma leitura de Los sonetos de la muerte, de sua autoria.

Com essa perspectiva, parto das reflexões de Stuart Hall, em Identidade e diferença, para quem a identidade é uma produção social e surge através das relações culturais e sociais que evidenciam uma marca representativa que é a diferença, ou seja, a identidade se constitui em uma afirmação que resulta em reconhecer diferenças entre os grupos sociais. Tanto a identidade quanto a diferença são, pois, uma construção de declarações (positivas e negativas) com relação a outrem.

É precisamente porque as identidades são construídas dentro e não fora do discurso que precisamos compreendê-las como produzidas em locais históricos e institucionais específicos, no interior de formações e práticas discursivas, por estratégias e iniciativas específicas. Além disso, elas emergem no interior do jogo de modalidades específicas de poder e são, assim, mais produto da marcação da diferença e da exclusão do que o signo de uma unidade idêntica, naturalmente constituída, de uma mesmidade que tudo inclui, uma identidade sem costuras, inteiriça, sem diferenciação interna (HALL, 2000, p. 109).

1 Mestra em Letras: Linguagem e Identidade pela Universidade Federal do Acre (2010) e Professora dessa mesma instituição, lotada no Centro de Educação, Letras e Artes. 
Desse modo, para Stuart Hall a identidade se constitui por meio da diferença, da relação com a outridade na medida em que nos constituímos como sujeitos, na identificação do "eu” como “outro". Hall (2000) considera que a identidade está implicada profundamente na representação, nos diferentes sistemas de representações têm efeitos profundos na maneira como as identidades são localizadas e representadas. Dentro das relações espaço-temporais encontramos a figura de Lucila Godoy Alcayaga, que mais tarde se tornaria outra - Gabriela Mistral. Podemos considerar que a autora estabelece dentro de seu discurso literário um conflito identitário, representado em uma luta entre seus conflitos internos de quem foi e quem era, na retomada de momentos vivenciados e que voltam à tona como Lucila e o que viveu, então, como Gabriela Mistral.

A trajetória de Lucila está marcada por representações em uma esfera social rígida, pelo o não-aceito, pelo convencionalismo rompido através do abandono de seu pai, numa família composta somente de mulheres, sustentada pela irmã que era professora, pela acusação de roubo que a fez ser discriminada na escola, por não chegar a ter uma formação escolar regular, e bem mais tarde, por supostamente ter um filho sem ser casada, ou seja, as circunstâncias de sua vida estão na contramão do que se padroniza na sociedade de sua época, e que ainda apresenta vestígios na nossa em se tratando da mulher - o não poder ser.

Vivendo em um tempo em que a mulher começa a buscar seu espaço, percebe-se em Gabriela uma mulher diferenciada, podemos considerá-la como sujeito marcado historicamente por acontecimentos profundos e marcantes, que não vê saída do que negar a sua própria identidade, na construção de um nome que supostamente não mais seria negado e que lhe dará lugar devido, que Lucila não alcançaria.

Segundo Ana Pizarro (1994), Gabriela buscava um reconhecimento de sua escrita e de sua pessoa como artista. Uma legitimação em uma sociedade sexista que julgava duramente a mulher. Na tentativa de uma visibilidade, na busca pela legitimidade e uma imagem diferenciada, "rompe" com sua história, "rompe" com sua identidade ou como declara Pizarro (1994) dedica seus esforços na construção de seu projeto maior, o projeto Gabriela. No entanto, manter a imagem ou o nome de Gabriela 
Mistral lhe custou muito, evidenciando um descentramento identitário. Como já dito, a "fuga" de Lucila sinaliza, inevitavelmente, uma Gabriela marcada como sujeito histórico por preconceitos, marginalidade, contradições e dualidades.

Conforme indica Silva (2009), a questão de gênero na literatura sempre foi alvo da crítica literária. Para alguns críticos, a literatura feminina apresenta uma identidade particular que remete ao próprio gênero e, portanto, à condição da mulher. De modo discriminatório considera-se essa literatura como "débil". A literatura latino-americana assume em um contexto internacional uma concepção preconceituosa de que consiste em uma literatura periférica. Essa concepção se manifesta dentro da própria latino-americana em relação à literatura de autoria feminina que por muito tempo foi considerada em seu próprio ambiente (contexto) como periférica. Uma literatura que não tem nada a dizer, pois recai sempre no mesmo.

A crítica literária considera que a literatura de autoria feminina se limita a uma manifestação de emoções. As mulheres por muito tempo, mesmo nas classes altas, eram proibidas de escrever e destinadas apenas a serem leitoras piedosas e apaixonadas (SILVA, 2009). Segundo Mataix (2003), o fato de as mulheres lerem e escreverem poemas no século XIX era considerado um verdadeiro desacato aos modelos sociais dominantes (MATAIX, apud SILVA, 2009). A visão de trabalho a que deveria se dedicar as mulheres se limitava a afazeres domésticos e a subserviência do lar e marido. Numa limitação ou "clausura" em que tradicionalmente as mulheres sempre foram impostas. Gabriela Mistral viveu esse preconceito de modo muito intenso, sentiu profundamente o que é ser mulher em seu tempo, e uma mulher-escritora em seu país. Conforme Ana Pizarro,

Localizar en el contexto continental la linea discursiva de Gabriela nos permite visualizar mejor por una parte el espacio que ella ocupa, su marco de referencia estética, así como la situación de enunciación desde donde ésta emerge. Dentro de este marco y en una perspectiva bistoriográfica, la función de su discurso, como su operatividad posterior en la construcción de la literatura de nuestro siglo, aparece como marginal (PIZARRO, 1994, p. 4).

Assim sendo, representa, pois, o lugar do discurso literário latino- 
americano e da mulher. Mistral é a representação da mulher dentre tantas mulheres que como por meio de um espelho reflete a partir da linguagem sua condição em um mundo marcado histórico e socialmente pela negação do gênero (como bem considera Cecília Meireles sobre as escritoras latinoamericanas).

Conforme Silva, a crítica feminista francesa irá discutir sobre a existência de marcas do feminismo no discurso e na escrita de autoria feminina. Ao analisar uma conferência de Cecília Meireles, Silva demonstra que a escritora brasileira aponta algumas considerações sobre "expressão feminina" ou "rasgos bem femininos" na escrita de autoria feminina, especialmente, no que se refere à América Latina, considera que as poetisas latino-americanas do século XIX ainda não tinham muitas pretensões com seus versos: a poetisa bendiz o amado. Contente apenas com as lembranças do passado (SILVA, 2009, pp. 106-107).

Se formos considerar o espaço e o processo de escrita, notamos conforme Chartier e Hérbrad analisando Michel de Certeau que

o ato de escrever que produz, inicialmente, o "publicável", o escrito aberto à multiciplicidade de leituras, torna-se o ato que, quase necessariamente, constitui um espaço privado. Para escrever é preciso um lugar próprio. (...) A escritura é uma técnica violenta do corpo, do domínio do gesto, da solidão, do frente a frente consigo mesmo (CHARTIER; HÉRBRAD, 1981, pp. 42-43).

Desse modo, verificamos que a escrita de literatura feminina não consiste apenas em uma "escrita de amor", em Mistral percebe-se que o poema traz elementos identitários profundos que revelam nos meandros das letras as angústias vividas pela autora-mulher, um discurso que em versos revela e (des)revela o que seja essa autora no dizer e não-dizer de seus escritos, revela o que é ser mulher e mulher-escritora em determinado tempo histórico. Segundo Beatriz Sarlo, pensar no passado não é algo fácil. O passado é sempre conflituoso. Em relação à Gabriela Mistral seu passado se configurar em momentos de suscetíveis conflitos familiar, social, intelectual e íntimo que ressurge em suas obras, como bem aponta Vásquez.

Ainda conforme Vásquez (2011), "Es común en las narrativas de Gabriela Mistral, encontrar descripciones relativas a rechazos; al parecer 
era común que ella representara así muchas situaciones, sobre todo durante su vida en Chile y en sus relacionamientos con el país". Apesar da construção de um discurso cultural e literário diferenciados, vanguardista construído por Gabriela, sinalizado por Pizarro (1994), observamos a retomada do que ela foi e viveu, quando remete em seus poemas a terra, árvores, a infância, os gestos de sua mãe.

A autora fala através de Gabriela, todavia a partir da construção da memória de Lucila, da camponesa marcada pela dor, pela tristeza e desolação, que não podem ser esquecidos, ao contrário retornam como uma espiral, como algo que girando de um lado ao outro se encontram e se revelam novamente; como sugere Mendilow, "Somos a qualquer momento a soma de todos os nossos momentos, o produto de todas as nossas experiências" (MENDILOW apud LOWENTHAL, 1981, p. 64). Dessa forma, podemos concluir que a escrita de Mistral representa isso: ela é fruto de suas experiências. Ela precisaria viver sua vida de Lucila e Gabriela para ser a soma de todos esses momentos, para ser Gabriela Mistral.

Los sonetos de la muerte pode ser considerado um dos poemas mais conhecidos da autora e como alguns críticos alegam, marcam o início da "consagração" ou "nascimento" da escritora. A partir desses sonetos verifica-se sua importância poética, como sinaliza Rosalía Aller "el verdadero nacimiento poético de la autora" (HERNÁNDEZ, 2012.

O tema central da morte constitui-se em algo que acompanha a autora mudando o curso de sua vida. Morte de seu noivo, morte de seu pai, morte de sua mãe, morte de seu suposto filho e a morte de Lucila, sim a morte do que se é, mas que ressurge nos entremeios de sua escrita. Em especial, representam um momento de revelação muito evidente dos sentimentos da autora ante o amor perdido.

Logo na primeira parte do poema, verificamos o lamento, anseio e desejo perante a situação vivida da morte de seu amado ela "si pudiera le daría la calentura de la vida otra vez", conforme a primeira estrofe dos versos percebemos a aspiração por estar junto a seu amado, e conceder seus cuidados como uma mãe cuida de seu filho quando está doente. Gabriela Mistral como sugere Pizarro são duas e seu projeto Gabriela 
revela duas figuras que persistem em seus poemas - a figura da mãe e da professora. Duas representações que encontramos figuras distintas, mas que apresentam uma mesma essência - a instrução - ambas ensinam, tentam guiar, direcionar e cuidar.

Em continuação, vemos os seguintes versos "Lo pondrá en la tierra caliente con una dulzura que solo una madre/ hace con un hijo al dormiry la tierra se quedará suave como uma cunal cuando tiene un niño con dolores", evidencia-se a necessidade da escritora ou a identificação feminina, que apresenta forte em suas atitudes a característica materna, do sentimento de quem cuida e protege, de quem zela mesclando a dor de não poder assumir tal cuidado. Observa-se ainda a retomada da memória numa representação do cuidado e presença de sua mãe que se projeta na própria autora em relação ao amado. Nesse fragmento observamos ainda que, a autora demonstra a dor da morte, mas sua religiosidade, construída, inevitavelmente, no ambiente familiar.

Nesse soneto verificamos como apontam muitos estudiosos, sua religiosidade, a retomada em versos de elementos presentes na memória de Lucila-Gabriela como, as canções de cuna que são recordações de sua infância, a cidade pequena, as flores, a terra, a dor, o amor de sua mãe, o vazio, o anseio e esperança. O que sugere que "o passado nunca está morto, ele existe ininterruptamente na memória de pensadores e de homens imaginativos (...). O passado coexiste com o presente ao mesmo tempo em que se distingue dele" (HIGHET, apud, LOWENTHAL, 1981, pp. 64-65).

$\mathrm{Na}$ segunda parte do soneto, verifica-se profundo lamento e a vontade de morrer para a vida, em que o eu-lírico se rende indagando que seu corpo sofre, mas sua alma já não quer seguir com aquela dor. Tamanha dor a fazia está mais perto de seu amado, que poderia sentir sua presença sendo que ela já se sentia morta em vida, um sentimento de dor que somente poderá ser desfeito na eternidade. Em alguns instantes, a autora parece deixar pistas de que sabia o porquê de seu amado ir antes dela, mas reclama o fato dele cortar os laços. Não concebe porque o amor realiza esses desencontros sem piedade.

$\mathrm{Na}$ terceira estrofe, quando se refere às "Malas manos te llevaron ese 
día, en gozo viviamos, pero las malas manos te llevaron trágicamente", talvez esteja se referindo não somente ao ato trágico do suicídio, mas ao roubo que fora cometido por seu amado. Podemos considerar que outra vez se cala sobre fatos ou acontecimentos que talvez apenas os dois soubessem, e esse segredo ocasionava uma dor maior que a própria morte. Para alguns estudiosos, esse momento consiste na morte dos sonhos, mas, especialmente, no alívio "No séporque el amorno tuvopiedad, tú Señor es quiénpuede juzgarme, solo tú me comprendes" novamente retoma a religiosidade clamando ao seu Senhor, declarando-o único que pode julgar e compreender; temse alusão clara a um sentimento vivido antes (a traição do seu primeiro noivo). Observamos outra vez, a retomada de Lucila. É então Lucila que assim como tem que enterrar o corpo de seu amado, enterra junto com ele, o amor e seus sonhos. Observamos que não mais se verifica os amores "arrebatados" vividos por Gabriela após estes acontecimentos. A autora intenta resguardar sua vida sentimental, o que suscita diferentes especulações.

Considera que o eu-lírico revela em seus versos a verdadeira desolação e lamento de sua alma por nunca ter seu amado, em uma relação real. Ela estava noiva, não concretizou seus anseios, não viveu "os supostos sonhos ansiados pelas mulheres". Porém, nota-se que a morte é uma mescla de dor e alívio. Dor pelo desprendimento físico da perda e "alivio" de não voltar a viver a "traição do amor", de se render a separação eterna. Na verdade, como sugerem alguns estudiosos existe nos Sonetos uma contradição nos sentimentos. Assim como, a mescla de sentimentos desencontrados entre haver perdido seu amado, mas cantar a beleza de que não o perderá por outra mulher (esse último resulta ainda mais importante).

Dessa forma, percebemos que a morte representa o tema cume do soneto. Representa a negatividade do episódio crucial pelo qual passarão todos. O eu-lírico demonstra que ainda não estava preparado para esta morte. Lamentando e querendo estar em seu lugar. Pelas concepções de identidade que nos constituem como sujeitos no mundo, podemos considerar que a temática da morte é constituinte do sujeito como algo que não se quer e não se sabe quando, mas se sabe/ reconhece que é inevitável. A temática da morte revela a condição do eu-lírico frente à morte de seu 
amado (HERNANDEZ, 2012, p. 127). Revela a condição do ser humano diante de um episódio sem-igual, por isso, profundo, perturbador, conflituoso, angustioso, traumatizante e real. Essas características são ainda mais evidentes, pois resulta na própria trajetória da autora.

Segundo Bauman (2005), a contemporaneidade vive momentos de constantes mudanças e deslocamentos de seus atores sociais, pois vivemos em constante liquidez e incerteza do que realmente somos e a que lugar pertencemos, que leva a questionamentos de como podemos nos identificar com outros espaços e sujeitos por participarmos de múltiplas situações que, por vezes, não permitem essas associações.

Devemos considerar que as relações e condições humanas são, na maioria das vezes, condições de conflito. A afirmação da identidade é um campo de intensa luta. Afirmar não para nós, e sim para o outro, que existimos como sujeitos, que também somos detentores de direitos, de dignidade e de respeito resulta em uma luta que muitas vezes não chega a ter um fim.

Se observarmos a história, acontecimentos e rechazos vividos ao longo da vida da autora, mesmo quando desempenhava seu papel educativo e administrativo nos Liceus, identificamos que todas as circunstâncias levaram consciente e inconscientemente na negação de seu "eu". Gabriela Mistral ambicionava ser mais que uma professora ou escritora provinciana; desejava reconhecimento de sua obra literária, logrando êxito a partir de diferentes e comprometedoras "articulações" sociais. Por circunstâncias e "silêncios" de sua vida, Mistral passou parte dela negando sua identidade, negando seu verdadeiro "eu”, numa fuga desesperada por considerar-se não pertencente a um único lugar, ela se coloca como sujeito descentralizado e cosmopolita; mostra disso é o que sugerem alguns críticos, em especial, Pizarro (1994) que, como dito anteriormente, sinaliza que a autora empreendeu suas forças na construção de seu projeto "Gabriela Mistral", em que acreditava que sua produção estaria distanciada do que era "Lucila", todavia isto não significava que seus escritos não trariam las buellas de lo que fue. 


\section{Referências}

CHARTIER, A. M.; HÉRBRAD, J. "A invenção do cotidiano: uma leitura, usos". Tradução de Mariza Romero, In: Projeto História: Revista do Programa de Estudos Pós-Graduados em História e do Departamento de História da Pontifica Universidade Católica de São Paulo. São Paulo: Educ, 1981.

HALL, S. A identidade cultural na pós-modernidade. Trad. Tomaz Tadeu da Silva e Guacira Lopes Louro. Rio de Janeiro: DP\&A, 2003.

HALL, S. Identidade e Diferença: a perspectiva dos estudos sociais. Tomaz Tadeu da Silva (Org.). Petrópolis: Vozes, 2000.

HALL, S. La cuestión de la identidad cultural. Introducción: la identidaden cuestión. Disponível em: http:/ / antroporecursos.files.wordpress.com/2009/03/hall-s-dugay-p-1996-cuestiones-de-identidad-cultural.pdf

HERNÁNDEZ, D. O. P. “¿Que no sé de la muerte?” Lo tanático en los Sonetos de la muerte de Gabriela Mistral, 2012. Disponível em: http://www.filo.unt.edu. ar/rev/telar/revistas/10/pos_perez_h.pdf

LOWENTHAL, D. "Conhecendo o passado". Tradução de Lúcia Haddad, In: Projeto História: Revista do Programa de Estudos Pós-Graduados em História e do Departamento de História da Pontifica Universidade Católica de São Paulo. São Paulo: EDUC, 1981.

MASSONE, J. A. “El sostenido dolor de 'Los Sonetos de la Muerte”, In: Revista Musical Chilena,1981. XXXV, n. 153-155, p. 75-81. Disponível em: http://www. revistamusicalchilena.uchile.cl/index.php/RMCH/article/viewFile/626/528.

MÜNNICH, S. Ana Pizarro. Gabriela Mistral. El proyecto de Lucila. Santiago: LOM Ediciones, 2005. In: Taller de Letras n. 40: 223-247, 2007. Disponível em: http://www7.uc.cl/letras/html/6_publicaciones/pdf_revistas/taller/tl40_17. pdf.

NASCIMENTO, F. L. Gosto, sabores e dissabores: contatos culturais entre as fronteiras da Amazônia acreana. Rio Branco: PPGLI/UFAC, 2010 [Dissertação de Mestrado].

NAVARRETE, C. Reseñas. Ana Pizarro. Gabriela Mistral. El proyecto de Lucila. Santiago: LOM Ediciones, 2005. Disponible en http://analesliteraturachilena. cl/wp-content/uploads/2011/05/a7_20.pdf.

PIZARRO, A. Gabriela Mistral en el discurso cultural. Archivo Chile História Político Social - Movimento Popular. Centro de Estudios "Miguel Enríquez CEME. In: De ostras y caníbales. Ensayos sobre la cultura latinoamericana, Ed. Universidad de Santiago, Santiago, Chile, 1994. Disponible en http://www. archivochile.com/Cultura_Arte_Educacion/gm/s/gmsobre0008.pdf.

Projeto História: revista do Programa de Estudos Pós-Graduados em História e do Departamento de História da Pontifica Universidade Católica de São Paulo. São Paulo: EDUC, 1981. 
SARLO, B. Tempo passado: cultura da memória e guinada subjetiva. Tradução Rosa Freire d'Aguiar. - São Paulo: Companhia das Letras: Belo Horizonte, UFMG, 2007.

SILVA, J. S. Vozes femininas da poesia latino-americana: Cecília e as poetisas uruguaias. - São Paulo: Cultura Acadêmica, 2009. p.224

VÁSQUEZ, C. S. Gabriela Mistral: tácticas de una maestra viajera. In: Revista Colombiana de Educación no.61 Bogotá June/Dec. 2011. Disponível em: http:// www.scielo.org.co/scielo.php?pid=S0120-39162011000200012\&script $=$ sci_ arttext

Data de recebimento: $15 / 12 / 2018$

Data de aceite: $28 / 12 / 2018$ 